\title{
Efficacy of TNF inhibitors in advanced ankylosing spondylitis with total spinal fusion: case report and review of literature
}

This article was published in the following Dove Press journal:

Open Access Rheumatology: Research and Reviews

\author{
Man R Shim \\ Department of Medicine, Rheumatology \\ Division, David Geffen School of \\ Medicine, University of California, Los \\ Angeles, CA, USA
}

\begin{abstract}
Ankylosing spondylitis (AS) is a chronic and progressive inflammatory disorder that primarily affects the axial skeleton. Unfortunately, diagnosis of AS is often delayed compared to other rheumatologic conditions. It is not uncommon for patients to already have an advanced disease when the correct diagnosis is eventually made. TNF inhibitors are wellknown and effective treatment options in patients with AS. However, many clinical trials have excluded patients with advanced AS. This paper reports a 45 -year-old male with newly diagnosed AS with already fused sacroiliac joints, lumbar spine, and cervical spine. Due to persistent and severe pain despite having taken multiple NSAIDs, etanercept was prescribed. After 4 years of treatment, the patient continues to experience marked improvement of his AS symptoms without any significant adverse effects. This case illustrates etanercept can be an effective treatment in patients with advanced AS and is well tolerated. An extensive literature review is also carried out regarding this topic.
\end{abstract}

Keywords: ankylosing spondylitis, advanced, tumor necrosis factor inhibitors, total spinal fusion

\section{Introduction}

Ankylosing spondylitis (AS) is a progressive immunomediated disorder characterized by inflammation and new bone formation, predominantly in the axial skeleton, although peripheral joint involvement, enthesitis, and extra-articular manifestations can also be observed to varying degrees. The spinal inflammation promotes formation of intervertebral syndesmophytes and osseous fusion, which can lead to both structural and functional impairments and decreased quality of life (QOL). ${ }^{1}$ There is a strong association of AS with HLA-B27 genetic background. ${ }^{2}$ The most common symptom is inflammatory back pain. ${ }^{3}$ Despite reported prevalence of AS between $0.2 \%-0.5 \%$ in the United States, AS accounts for only a minority of cases of chronic low-back pain. ${ }^{4}$ Delay in diagnosis of AS by many years is common, which may be in part due to failure of recognition by non-rheumatologists. ${ }^{5}$ Not initiating treatment in a timely manner in turn can result in worse long-term outcomes, due to irreversible new bone formation in the axial skeleton, pain, loss of spinal function, and diminished QOL. ${ }^{6}$ Although there is currently no cure for AS, treatment with TNF inhibitors (TNFis) has significantly improved symptoms, signs, and QOL in patients with $\mathrm{AS}^{7}$ Biologic therapy is recommended when disease activity is high despite treatment with at least two NSAIDs and physiotherapy. ${ }^{8}$ Unfortunately, there are only limited data available regarding the
Correspondence: Man R Shim Department of Medicine, Rheumatology Division, David Geffen School of Medicine, University of California, UCLA Health Beverly Hills, 864I Wilshire

Boulevard - Suite 210, Beverly Hills, CA 90211 USA

Tel + I 3108557002

Fax + I 3108557003

Email mrshim@mednet.ucla.edu 
efficacy of TNFis in patients with advanced AS, because most randomized clinical trials have excluded this subgroup.

\section{Case report}

The patient was a 45 -year-old male with past medical history significant for obesity and hypertension who presented to the clinic with chronic and progressive low-back pain and neck pain for over 10 years. Written informed consent was provided by the patient to have the case details and any accompanying images published. Institutional approval was not required to publish the case details. The pain was severe and constant, which he rated 8 out of 10 on a pain scale. The pain was worse during the second half of the night, and awakened him intermittently. It was also severe in the morning, with associated stiffness lasting approximately 2 hours. The pain was aggravated by prolonged rest and alleviated with activity. In recent years, he had also noticed substantial limitation of movement in the neck and lower back. He had undergone physical therapy and taken maximum doses of several NSAIDs, which were only minimally efficacious. He denied history of uveitis, psoriasis, peripheral joint pain, or gastrointestinal symptoms suggestive of active inflammatory bowel disease.

Physical examination revealed limited movement of the cervical spine, with occiput-to-wall distance of $5 \mathrm{~cm}$. He also had reduced chest expansion of only $2 \mathrm{~cm}$ and strikingly reduced range of motion at the lumbar spine, with abnormal modified Schober's test of $12 \mathrm{~cm}$ from $10 \mathrm{~cm}$ upon forward flexion. He had tenderness over the bilateral sacroiliac joints and the lumbar spine. However, he did not exhibit any inflammatory-appearing rashes, abnormal nail changes, or active synovitis, enthesitis, or dactylitis in the peripheral joints. Blood work showed positive HLA-B27, elevated erythrocyte-sedimentation rate (ESR) of 50 and elevated CRP of $1.8 \mathrm{mg} / \mathrm{dL}$ (normal defined as $<0.8 \mathrm{mg} / \mathrm{dL}$ ). Plain radiographic imaging studies were notable for the fusion at the sacroiliac iliac joint bilaterally (Figure 1), bamboo spine at the lumbar spine (Figure 2), and ankyloses of the cervical spine (Figure 3). Bath Ankylosing Spondylitis Disease Activity Index (BASDAI) score was 5.7, patient global assessment of disease 8, total back pain 8, Bath Ankylosing Spondylitis Functional Index (BASFI) score 6.3, and inflammation (mean of BASDAI questions 5 and 6 for morning stiffness) score 7.

On the basis of the 1984 modified New York criteria, ${ }^{9}$ the patient was diagnosed with AS. Due to limited efficacy

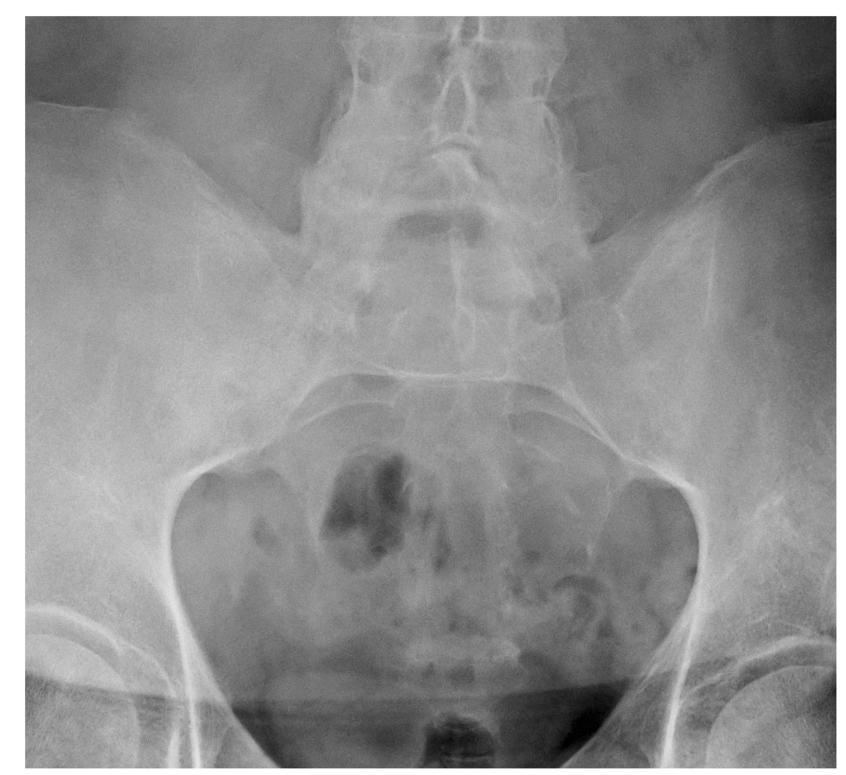

Figure I The sacroiliac joints are fused.

of prior treatments with NSAIDs and physiotherapy, the decision was made to start TNFis, specifically etanercept. Approximately 3 months into therapy, the patient reported marked improvement of his symptoms. His ESR and CRP had normalized to 10 and $0.4 \mathrm{mg} / \mathrm{dL}$, respectively. In addition, BASDAI score also improved from 5.7 to 1.7, BASFI from 6.3 to 4.2, patient global assessment of disease from 8 to 2 , total back pain from 8 to 2 , and inflammation (mean of BASDAI questions 5 and 6 for morning stiffness) from 7 to 1. As such, he easily met the Assessment of Spondyloarthritis International Society 40 improvement criteria. After 4 years of ongoing treatment with etanercept, he continues to do well clinically without experiencing any adverse effects. He is also able to work and perform all his activities of daily living without any issues or problems.

\section{Discussion}

Compared to other types of spondyloarthritis, patients with AS are more likely to have symmetric sacroiliitis, stronger association with HLA-B27, and extensive spinal fusion. ${ }^{10}$ Needless to say, the functional disability, pain, and overall disease burden associated with AS are immense. ${ }^{11}$ To make matters worse, the delay between the onset of associated symptoms and diagnosis of AS frequently takes longer than 10 years. ${ }^{12}$ As such, it is not uncommon for patients to already have advanced disease at the time of diagnosis. In AS, some patients may achieve low disease activity over time, due to reaching a "burnout" state; however, other patients may still retain high disease activity despite being 


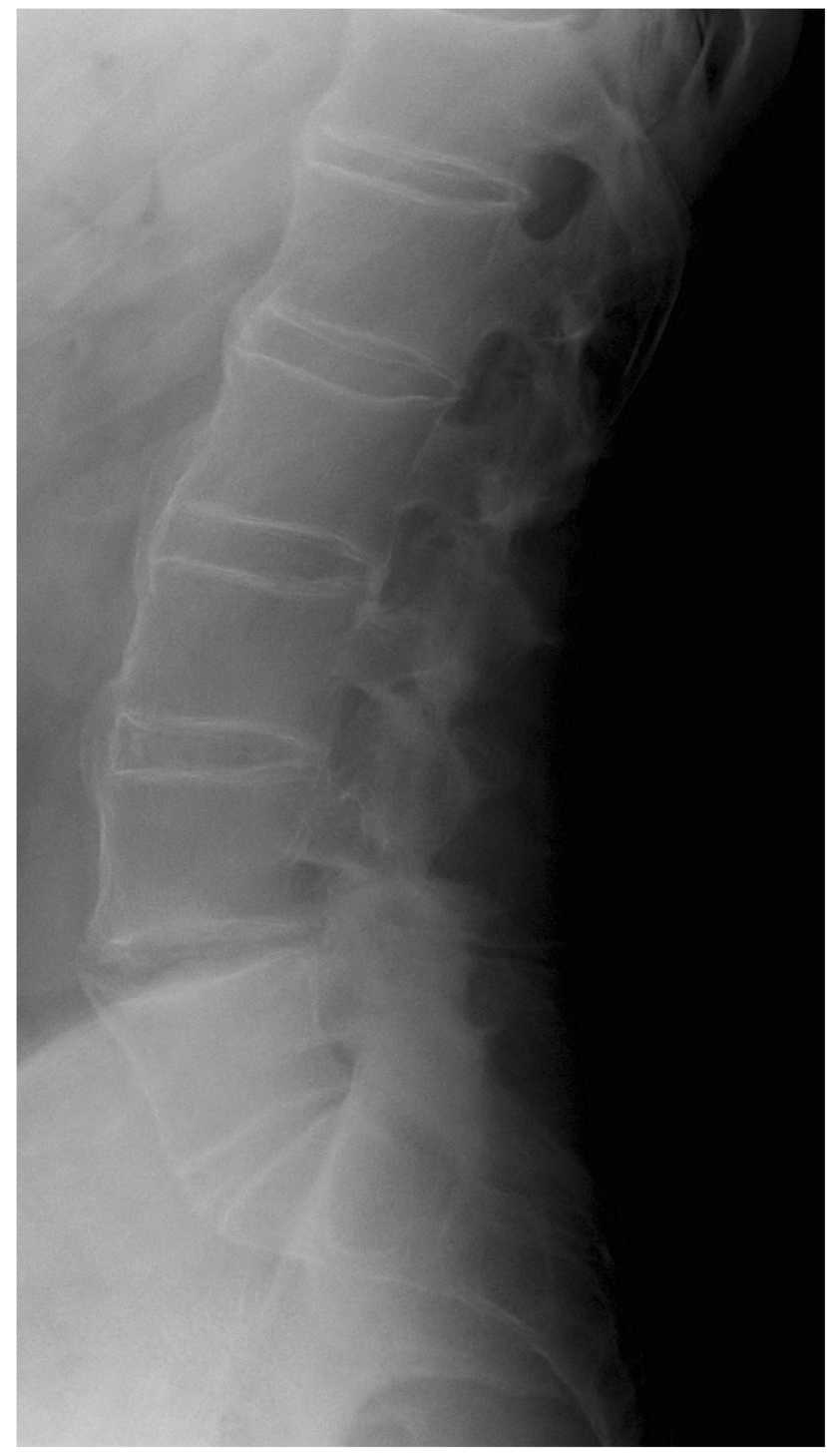

Figure 2 Bridging syndesmophytes at multiple levels of the lumbar spine along the anterior fibers, consistent with a bamboo spine.

in the most advanced radiographic grading-system stage, $\mathrm{i}$. e.,stage V, as proposed by Braun et al. ${ }^{13}$ Unfortunately, there is a paucity of data available in patients with advanced AS, because they are frequently excluded from clinical trials.

To my knowledge, there have been only a handful of studies that have reported the efficacy of TNFis in patients with advanced AS: two were observational studies without a control group for infliximab ${ }^{14}$ and adalimumab, ${ }^{15}$ one was a post hoc analysis of adalimumab in a phase III study, where eleven patients with total spinal ankylosis were evaluated, ${ }^{16}$ and another was a 12-week randomized double-blind placebo-controlled multicenter study of 82 advanced AS patients with etanercept. ${ }^{17}$ The results of these studies all

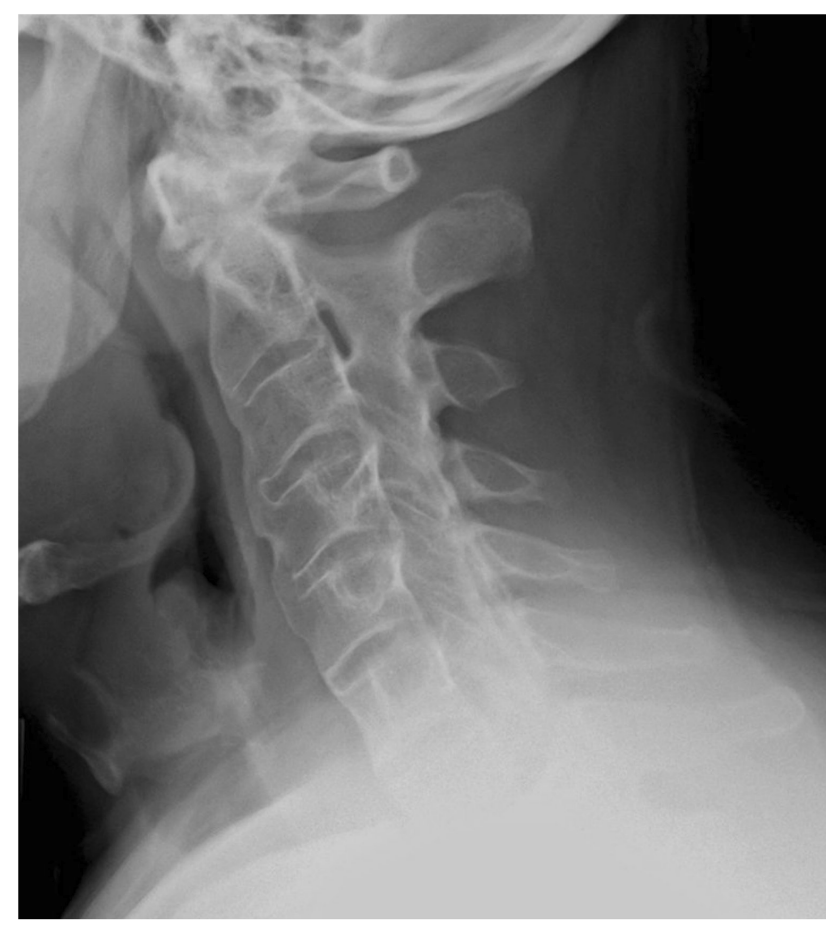

Figure 3 Mature ankylosis of the cervical spine with straightening.

suggested reduction of symptoms and signs of AS in patients with advanced but still active AS, similar to those in whom AS was not radiographically advanced. This was also the case for my patient, whose BASDAI score, BASFI score, severity of morning stiffness, ESR, and CRP all improved significantly upon treatment with etanercept. In addition, my patient is tolerating etanercept well without any unexpected adverse events, similarly to the patients in these studies who were treated with various TNFis.

To summarize, having advanced AS is not a contraindication to TNFi therapy as long as patients have active disease and have failed to respond adequately to at least two NSAIDs and physiotherapy. High baseline BASDAI score and CRP seem to be better predictors of clinical response to TNFis, since AS patients with varying degrees of ankylosis experience similar benefits from the treatment. ${ }^{14-19}$ Several TNFis have been approved for AS, and their efficacy appears to be comparable, despite the lack of head-to-head comparisons. ${ }^{8}$ Etanercept was chosen for my patient due to his insurance company's preference, although monoclonal antibodies, i.e., infliximab, adalimumab, certolizumab, and golimumab, would have been better choices had he had concomitant uveitis or inflammatory bowel disease. ${ }^{20,21}$ However, more studies need to be performed to determine if or when biologics should be tapered in a patient like mine, who achieved sustained remission on chronic TNFi therapy. 
Furthermore, the current guidelines are not clear on whether patients should be switched to another TNFi or changed to anti-IL17 therapy if the ongoing TNFi therapy fails.

\section{Key points}

Having advanced AS and total spinal ankylosis is not a contraindication to TNFi if patients fail conventional treatment with NSAIDs and physiotherapy and disease is still active, i.e., elevated CRP, elevated BASDAI score, and active inflammation seen on magnetic resonance imaging. Improvement of symptoms, signs, and QOL of AS patients with advanced disease on TNFis are comparable to those in whom AS is not as radiographically advanced. Further studies need to be performed to determine whether switching to another TNFi or anti-IL17 therapy should be considered when ongoing TNFi therapy fails. Also, an ideal time to initiate a tapering regimen of biologics should be ascertained when patients achieve sustained remission on TNFis.

\section{Disclosure}

The author reports no conflicts of interest in this work.

\section{References}

1. Braun J, Sieper J. Ankylosing spondylitis. Lancet. 2007;369:13791390. doi:10.1016/S0140-6736(07)60635-7

2. Kahn MA. Epidemiology of HLA-B27 and arthritis. Clin Rheumatol. 1996;15:10-12.

3. Sieper J, van der Heijde D, Landewé R, et al. New criteria for inflammatory back pain in patients with chronic back pain: a real patient exercise by experts from the Assessment of SpondyloArthritis international Society (ASAS). Ann Rheum Dis. 2009;68:784-788. doi:10.1136/ard.2008.101501

4. Reveille JD. Epidemiology of spondyloarthritis in North America. Am J Med Sci. 2011;341(4):284-286. doi:10.1097/MAJ.0b013e31820f8c99

5. van Hoven L, Luime J, Han H, Vergouwe Y, Weel A. Identifying axial spondyloarthritis in Dutch primary care patients, ages 20-45 years, with chronic low back pain. Arthritis Care Res (Hoboken). 2014;66:446-453. doi:10.1002/acr.22180

6. Seo MR, Baek HL, Yoon HH, et al. Delayed diagnosis is linked to worse outcomes and unfavourable treatment responses in patients with axial spondyloarthritis. Clin Rheumatol. 2015;34:1397-1405. doi:10.1007/s10067-014-2768-y

7. Callhoff J, Sieper J, Weiß A, Zink A, Listing J. Efficacy of TNF $\alpha$ blockers in patients with ankylosing spondylitis and non-radiographic axial spondyloarthritis: a meta-analysis. Ann Rheum Dis. 2015;74:1241-1248. doi:10.1136/annrheumdis-2014-205322
8. van der Heijde D, Ramiro S, Landewé R, et al. 2016 update of the ASAS-EULAR management recommendations for axial spondyloarthritis. Ann Rheum Dis. 2017;76:978-991. doi:10.1136/annrheumdis2016-210770

9. van der Linden S, Valkenburg HA, Cats A. Evaluation of diagnostic criteria for ankylosing spondylitis. A proposal for modification of the New York criteria. Arthritis Rheum. 1984;27:361-368.

10. Perez Alamino R, Maldonado Cocco JA, Citera G, et al.; RESPONDIA Group. Differential features between primary ankylosing spondylitis and spondylitis associated with psoriasis and inflammatory bowel disease. $J$ Rheumatol. 2011;38:1656-1660. doi:10.3899/jrheum.101049

11. Boonen A, van der Linden SM. The burden of ankylosing spondylitis. J Rheumatol. 2006;33(Suppl. 78):4-11.

12. Deodhar A, Mease PJ, Reveille JD, et al. Prevalence of axial spondyloarthritis among undiagnosed chronic back pain patients in the United States. Ann Rheum Dis. 2014;73(Suppl 2):198-199. doi:10.1136/annrheumdis-2012-202603

13. Braun J, van der Heijde D, Dougados M, et al. Staging of patients with ankylosing spondylitis: a preliminary proposal. Ann Rheum Dis. 2002;61(Suppl. 3):19-23. doi:10.1136/ard.61. suppl_3.iii19

14. Cheung PP, Tymms KE, Wilson BJ, et al. Infliximab in severe active ankylosing spondylitis with spinal ankylosis. Intern Med J. 2008;38:396-401. doi:10.1111/j.1445-5994.2007.01599.x

15. Rudwaleit M, Olivieri I, Boki KA, et al. Adalimumab is effective and well tolerated in treating patients with ankylosing spondylitis who have advanced spinal fusion. Rheumatology (Oxford). 2009;48:551557. doi:10.1093/rheumatology/kep022

16. van der Heijde D, Pangan AL, Schiff MH, et al.; ATLAS Study Group. Adalimumab effectively reduces the signs and symptoms of active ankylosing spondylitis in patients with total spinal ankylosis. Ann Rheum Dis. 2008;67:1218-1221. doi:10.1136/ $\operatorname{ard} .2007 .082529$

17. Dougados M, Braun J, Szanto S, et al. Efficacy of etanercept on rheumatic signs and pulmonary function tests in advanced ankylosing spondylitis: results of a randomised double-blind placebo-controlled study (SPINE). Ann Rheum Dis. 2011;70:799-804. doi:10.1136/ $\operatorname{ard} .2010 .139261$

18. Maneiro JR, Souto A, Salgado E, Mera A, Gomez-Reino JJ. Predictors of response to TNF antagonists in patients with ankylosing spondylitis and psoriatic arthritis: systemic review and meta-analysis. RMD Open. 2015;1:e00017. doi:10.1136/rmdopen-2014-000017

19. Landewé R, Braun J, Deodhar A, et al. Efficacy of certolizumab pegol on signs and symptoms of axial spondyloarthritis including ankylosing spondylitis: 24-week results of a double-blind randomised placebo-controlled Phase 3 study. Ann Rheum Dis. 2014;73:39-47. doi:10.1136/annrheumdis-2013-204231

20. Fabiani C, Vitale A, Rigante D, et al. Efficacy of anti-tumour necrosis factor- $\alpha$ monoclonal antibodies in patients with non-infectious anterior uveitis. Clin Exp Rheumatol. 2019;37(2):301-305.

21. Nielsen OH, Ainsworth MA. Tumor necrosis factor inhibitors for inflammatory bowel disease. N Engl J Med. 2013;69:754-762. doi:10.1056/NEJMct1209614 


\section{Publish your work in this journal}

Open Access Rheumatology Research and Reviews is an international, peer-reviewed, open access journal publishing original research, reports, editorials, reviews and commentaries on all aspects of clinical and experimental rheumatology in the clinic and laboratory including the following topics: Pathology, pathophysiology of rheumatological diseases; Investigation, treatment and management of rheumatological diseases; Clinical trials and novel pharmacological approaches for the treatment of rheumatological disorders. The manuscript management system is completely online and includes a very quick and fair peer-review system, which is all easy to use. Visit http://www.dovepress.com/testimonials.php to read real quotes from published authors. 